Amory and Amory correctly note that grapefruit juice inhibits CYP3A4. Indeed, the same phenomenon may be seen with intact grapefruit segments. ${ }^{4}$ This effect is confined to intestinal rather than hepatic CYP3A4, and significant increases in drug levels are most likely with CYP3A4 substrates that normally undergo a high degree of presystemic metabolism. ${ }^{5}$ With the exception of cisapride (which is no longer in widespread use), this is not the case for most of the CYP3A4 substrates implicated in the genesis of torsades de pointes. Nevertheless, a recognition of the potential effects of grapefruit on drug bioavailability is essential, given the multitude of drugs metabolized by CYP3A4.
Barbara A. Liu, M.D.

David N. Juurlink, M.D., Ph.D.

Sunnybrook and Women's College Health Sciences Centre Toronto, ON M4N 3M5, Canada

1. Roden DM. Drug-induced prolongation of the QT interval. N Engl J Med 2004;350:1013-22.

2. Czekalla J, Beasley CM Jr, Dellva MA, Berg PH, Grundy S. Analysis of the QTc interval during olanzapine treatment of patients with schizophrenia and related psychosis. J Clin Psychiatry 2001;62:191-8. 3. Harrigan EP, Miceli JJ, Anziano R, et al. A randomized evaluation of the effects of six antipsychotic agents on QTc, in the absence and presence of metabolic inhibition. J Clin Psychopharmacol 2004;24: 62-9.

4. Dreier JP, Endres M. Statin-associated rhabdomyolysis triggered by grapefruit consumption. Neurology 2004;62:670.

5. Bailey DG, Dresser GK. Interactions between grapefruit juice and cardiovascular drugs. Am J Cardiovasc Drugs 2004;4:281-97.

\title{
Birth Weight and Breast Cancer
}

TO THE EDITOR: Ahlgren et al. (Oct. 14 issue) ${ }^{1}$ report the importance of both birth weight and childhood growth on the risk of breast cancer. Although the authors do not provide information about early growth (from the postnatal period to the age of eightyears) or birth length, the size of their study permits additional analyses to enhance our understanding of how growth patterns relate to disease. ${ }^{2}$ For example, were there any interactions between birth weight and childhood body size? Underweight babies who are well nourished in early childhood may have a greater risk of chronic disease later in life because of the hormonal changes that accompany rapid catch-up growth..$^{3-5}$ If so, persons with a low birth weight and peak height at an early age may have a greater increase in the risk of breast cancer than persons with a higher birth weight whose peak height occurs later. Babies who have "catchdown" growth may also have a different risk profile. Since the effect of menarche on breast cancer was mediated by other growth variables, models showing how measures of growth in infancy and early childhood are associated with markers of intermediate growth, including age at peak height, would provide crucial insight into the underlying pathways.

Mary Beth Terry, Ph.D.

Mailman School of Public Health

New York, NY 10032

mt146@columbia.edu
1. Ahlgren M, Melbye M, Wohlfahrt J, Sorensen TI. Growth patterns and the risk of breast cancer in women. N Engl J Med 2004; 351:1619-26.

2. Terry MB, Susser E. The impact of fetal and infant exposures along the life course. Int J Epidemiol 2001;30:95-6.

3. Stoll BA. Western diet, early puberty, and breast cancer risk. Breast Cancer Res Treat 1998;49:187-93.

4. Johnston LB, Dahlgren J, Leger J, et al. Association between insulin-like growth factor I (IGF-I) polymorphisms, circulating IGF-I, and pre- and postnatal growth in two European small for gestational age populations. J Clin Endocrinol Metab 2003;88:4805-10.

5. Ben-Shlomo Y, Holly J, McCarthy A, et al. An investigation of fetal, postnatal and childhood growth with insulin-like growth factor I and binding protein 3 in adulthood. Clin Endocrinol (Oxf) 2003; 59:366-73.

TO THE EDITOR: Ahlgren et al. report that birth weight and childhood growth influence the risk of breast cancer. We recently analyzed these relationships in a British cohort followed from birth to the age of 53 years. ${ }^{1,2}$ A higher risk of breast cancer at the age of 53 years was associated, in multivariable models, with the gain in height between 4 and 7 years and between 11 and 15 years and with the decrease in the body-mass index between 2 and 4 years. These effects were stronger the earlier the age at menarche, reflecting a similar pattern in the relationship between adult height and the risk of breast cancer (Table 1, top of page 305). Thus, it appears that women who grew faster in early childhood, had an earlier menarche, and continued to grow during the postpubertal period, reaching an adult height that was above av- 


\begin{tabular}{|c|c|c|c|c|}
\hline \multirow[t]{3}{*}{ Age at Menarche } & \multicolumn{3}{|c|}{ Model with All Childhood Growth Components' } & \multirow[t]{3}{*}{ Model with Adult Height: } \\
\hline & $\begin{array}{l}\text { Yearly Change in } \\
\text { BMI, 2.1-4.0 yr }\end{array}$ & $\begin{array}{l}\text { Yearly Change in } \\
\text { Height, 4.1-7.0 yr }\end{array}$ & $\begin{array}{l}\text { Yearly Change in } \\
\text { Height, 11.1-15.0 yr }\end{array}$ & \\
\hline & \multicolumn{3}{|c|}{ relative risk (95 percent confidence interval) } & \\
\hline$<12.5 \mathrm{yr}$ & $0.50(0.33-0.75)$ & $1.95(1.25-3.04)$ & $1.66(1.00-2.78)$ & $1.85(1.20-2.84)$ \\
\hline $12.5-13.4 \mathrm{yr}$ & $0.95(0.54-1.65)$ & $1.37(0.82-2.31)$ & $1.89(1.13-3.15)$ & $0.96(0.58-1.58)$ \\
\hline$\geq 13.5 \mathrm{yr}$ & $0.89(0.55-1.44)$ & $1.07(0.66-1.77)$ & $0.76(0.43-1.32)$ & $1.13(0.72-1.77)$ \\
\hline Linear trend』 & 0.01 & 0.001 & 0.01 & 0.02 \\
\hline Interaction 9 & 0.02 & 0.07 & 0.13 & 0.04 \\
\hline
\end{tabular}

* Data, which are from the Medical Research Council National Survey of Health and Development, are based on a total of 2187 women and 59 cases of breast cancer. ${ }^{1}$ BMI denotes body-mass index.

$\dagger$ Relative risks were estimated with the use of a logistic-regression model that included all growth components (height at 2.0 years of age; yearly changes in height from 2.1 to 4.0 years, 4.1 to 7.0 years, 7.1 to 11.0 years, 11.1 to 15.0 years, and 15.1 years to adulthood; BMI at 2.0 years of age; and yearly changes in BMI from 2.1 to 4.0 years, 4.1 to 7.0 years, 7.1 to 11.0 years, and 11.1 to 15.0 years). Results are shown only for anthropometric measures for which there was evidence that their effect on breast cancer was modified by age at menarche.

7 Relative risks were estimated with the use of a logistic-regression model that included only adult height, age at menarche, and their interaction.

$\int$ The likelihood-ratio test was used to assess linear trend in the age-at-menarche-specific relative risks.

9 The Wald test was used to assess the heterogeneity of the age-at-menarche-specific relative risks.

erage for their age at menarche, were at greatest risk. Our findings, although based on a limited number of cancers in relatively young women, may help elucidate the complex relations among childhood growth, the onset of menarche, and the risk of breast cancer that are described - but not explained - in the report by Ahlgren et al.

Bianca L. De Stavola, Ph.D. Isabel dos Santos Silva, M.D., Ph.D.

London School of Hygiene and Tropical Medicine London WClE 7HT, United Kingdom

bianca.destavola@Ishtm.ac.uk
Michael J. Wadsworth, Ph.D.

Royal Free and University College Medical School London WCIE 6BT, United Kingdom

1. De Stavola BL, dos Santos Silva I, McCormack V, Hardy RJ, Kuh DJ, Wadsworth ME. Childhood growth and breast cancer. Am J Epidemiol 2004;159:671-82.

2. dos Santos Silva I, De Stavola BL, Hardy RJ, Kuh DJ, McCormack VA, Wadsworth ME. Is the association of birth weight with premenopausal breast cancer risk mediated through childhood growth? $\mathrm{Br}$ J Cancer 2004;91;519-24.

DR. AHLGREN REPLIES: Inspired by Dr. Terry's comments and those of Dr. De Stavola and colleagues, we conducted a further analysis (Table 1, below);

\begin{tabular}{|c|c|c|c|c|}
\hline \multirow[t]{2}{*}{ Growth Variable } & \multicolumn{3}{|c|}{ Birth Weight } & \multirow[t]{2}{*}{$\begin{array}{c}\text { P Value } \\
\text { for Effect } \\
\text { Modification }\end{array}$} \\
\hline & Quintile 1 & Quintiles 2, 3, and 4 & Quintile 5 & \\
\hline \multicolumn{5}{|c|}{ relative risk (95 percent confidence interval)* } \\
\hline Age at peak growth & $0.88(0.80-0.97)$ & $0.91(0.86-0.97)$ & $0.88(0.79-0.98)$ & 0.79 \\
\hline Height at age 8 & $1.11(1.01-1.23)$ & $1.13(1.06-1.20)$ & $1.08(0.97-1.21)$ & 0.80 \\
\hline Height increase, age 8 to age 14 & $1.14(0.96-1.37)$ & $1.15(1.03-1.29)$ & $1.07(0.87-1.30)$ & 0.80 \\
\hline BMI at age 14 & $0.91(0.68-0.95)$ & $0.95(0.92-0.98)$ & $0.94(0.89-1.00)$ & 0.27 \\
\hline
\end{tabular}

* The relative risk is for each one-year increase in age at peak growth, each 5-cm increase in height, and each 1-unit increase in the body-mass index (BMI). 
we investigated whether birth weight modified the main results. As shown in Table 1, we found no significant effect modification.
Martin Ahlgren, M.D., Ph.D.

Statens Serum Institut DK-2300 Copenhagen, Denmark abk@ssi.dk

\section{Autoimmune Lymphoproliferative Syndrome and Perforin}

TO THE EDITOR: Clementi et al. (Sept. 30 issue) ${ }^{1}$ describe the occurrence of autoimmune lymphoproliferative syndrome (ALPS) and lymphoma in a patient carrying both a heterozygous Fas mutation and a heterozygous mutation in the perforin gene (Prf1). It is likely that, in addition to Fas mutations, associated genetic defects could contribute to the ALPS phenotype. ${ }^{2}$ However, the possibility that the described Prf1 variant, which resulted in the replacement of asparagine with serine at position 252 of the perforin protein (N252S), would be such an associated factor is questionable. Although this variant was identified in a patient with hemophagocytic lymphohistiocytosis, ${ }^{3}$ two additional Prf1 mutations (resulting in the replacement of glycine with arginine at position 45 [G45R] and the replacement of glycine with serine at position 149 [G149S]) were later found in this patient (our unpublished data), casting doubt about the pathogenicity of the N252S variant. ${ }^{4}$ In addition, this Prf1 variant is found in

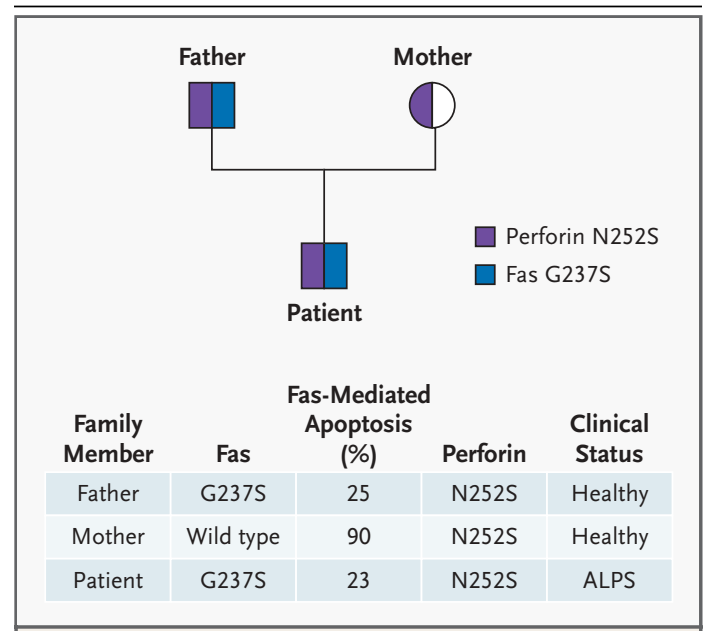

Figure 1. Pedigree of the Patient.

The Fas mutation was inherited from the patient's healthy father, whereas the Prf1 N252S variant was found in all members of this family.
18 percent of healthy controls and 10 percent of patients with ALPS type I (our unpublished data). We have also found a heterozygous Fas mutation (resulting in the replacement of glycine with serine at position 237 of Fas), together with the N252S Prf1 polymorphism, in a patient with ALPS and his healthy father (Fig. 1). The absence of any disease in the father strongly suggests that the heterozygous Prf1 N252S mutation in the patient described by Clementi et al. was not pathogenetic.

Frédéric Rieux-Laucat, Ph.D.

Françoise Le Deist, M.D., Ph.D.

Geneviève De Saint Basile, M.D., Ph.D.

INSERM Unité 429

75015 Paris, France

rieux@necker.fr

1. Clementi R, Dagna L, Dianzani U, et al. Inherited perforin and Fas mutations in a patient with autoimmune lymphoproliferative syndrome and lymphoma. N Engl J Med 2004;351:1419-24.

2. Rieux-Laucat F, Blachere S, Danielan S, et al. Lymphoproliferative syndrome with autoimmunity: a possible genetic basis for dominant expression of the clinical manifestations. Blood 1999;94:257582.

3. Stepp SE, Dufourcq-Lagelouse R, Le Deist F, et al. Perforin gene defects in familial hemophagocytic lymphohistiocytosis. Science 1999;286:1957-9.

4. Molleran Lee S, Villanueva J, Sumegi J, et al. Characterisation of diverse PFR1 mutations leading to decreased natural killer cell activity in North American families with haemophagocytic lymphohistiocytosis. J Med Genet 2004;41:137-44.

THE AUTHORS REPLY: RieuX-Laucat et al. question the role of the N252S perforin mutation in ALPS. We argue that it can contribute to ALPS for the following reasons. First, the frequency of N252S cited by Rieux-Laucat et al. is much higher than the published data. ${ }^{1}$ Moreover, Rieux-Laucat et al. do not mention the ethnic origins and actual numbers of subjects. To date, we have found this variant in 1 of 330 Italian controls ( 0.3 percent).

Second, we recently found the N252S variant in a second patient with ALPS type III who had a remarkable defect in natural-killer-cell activity. The frequency of N252S in patients with ALPS (2 of 25) and in controls ( 1 of 330 ) suggests its associa- 